\title{
Establishment of the College of Reviewers
}

\author{
Leonie Rowan, Parlo Singh and Jeanne Allen
}

The Asia-Pacific Journal of Teacher Education, and the Australian Teacher Education Association, are strongly committed to the support of high quality, high impact research that makes a significant contribution to the fields associated with teaching and teacher education. Consistent with this agenda we recognize the need to ensure that teacher educators are always and everywhere involved in interrogating the assumptions that underpin our decision making, and the beliefs that guide our actions. Central to this process is the peer review of our research outputs, with rigorous and thoughtful reviews playing a vital role in assuring the legitimacy, integrity and currency of research findings.

While it is easy to recognize that the capacity to engage meaningfully, critically and, of course, respectfully with papers submitted for review is a central requirement for quality reviewers, the amount of work associated with the reviewing process is too easily over looked. As part of our ongoing commitment to fostering the growth of the profession, and supporting the publication of research of the highest quality, we are pleased to announce the establishment of a College of Reviewers for the Asia-Pacific Journal of Teacher Education. Members of the College of Reviewers are selected on the basis of their involvement in research associated with teacher education, the quality and care of the reviews they provide, and their commitment to the aims and objectives of the AsiaPacific Journal of Teacher Education, and the Australian Teacher Education Association. We take great pleasure in introducing the first members of our newly established College of Reviewers and thank them for their willingness to take on this important service to their peers, and to the profession. 
Dr. Angelina Ambrosetti

Dr. Theresa Bourke

Dr. Elizabeth Curtis

A/Prof. Janet Dyment

A/Prof. Jo-Anne Ferreira

A/Prof. Susanne Gannon

Dr. Jess Harris

A/Prof. Deborah Heck

Dr. Manuela Heinz

Dr. Margaret Marshman

A/Prof. Madonna Stinson

A/Prof. Bonnie Yim
Central Queensland University

Queensland University of Technology

Queensland University of Technology

University of Tasmania

Southern Cross University

Western Sydney University

University of Newcastle

University of the Sunshine Coast

National University of Ireland

University of the Sunshine Coast

Griffith University

Deakin University
Australia

Australia

Australia

Australia

Australia

Australia

Australia

Australia

Ireland

Australia

Australia

Australia 